\title{
Estimation of evapotranspiration using a simulation model
}

\author{
M. H. Ali ${ }^{1}$, H. Paul ${ }^{2}$ and M. R. Haque ${ }^{3}$ \\ ${ }^{1}$ Faculty of Civil \& Environmental Engineering, University Malaysia Pahang, ${ }^{2}$ Department of Irrigation \& Water \\ Management, Bangladesh Agricultural University and ${ }^{3}$ Department of Irrigation \& Water Management, Bangladesh \\ Agricultural University, Mymensingh 2202, Bangladesh. Email: mha_bina@yahoo.com
}

\begin{abstract}
Practical methods for the accurate estimation of water requirement for irrigated agriculture are essential. Simulation model is a useful tool to estimate water balance in the crop field. In this study, the BUDGET model was used to evaluate its performance to simulate water balance in wheat field. The BUDGET model is composed of a set of validated subroutines describing the various processes involved in water extraction by plant roots and soil water movement in absence of a water table. The model was run to simulate evapotranspiration values with the actual observed weather, crop and soil data for three years (2002-2005), obtained from experimental Station of Bangladesh Institute of Nuclear Agricultural (BINA). The input data of model are separated into four stages and the value of $\mathrm{K}_{\mathrm{c}}$ and root depth are different for each stage. Evaluation of model performance is done with both graphical display and statistical criteria. The simulated values fall close to 1:1 line, indicating better performance. The statistical parameters such as standard deviation (SD), standard error (SE), coefficient of variation (CV) of simulated and actual evapotranspiration values are found 21.07 and 29.23; 4.49 and 6.23; and 38.03 and 50.75, respectively. Both the standard error and coefficient of variation for simulated values are found lower than the observed values indicating stability of the model output. The coefficient of determination value $\left(R^{2}=0.83\right)$ is high for this model, which indicates good simulation performance. The relative error $(R E)$ is 23.28 percent and model efficiency (EF) is 78.95 percent which means that the simulation of actual evapotranspiration is satisfactory. The value of Index of agreement (IA) is 0.918 which indicates a very good performance of the model. The overall statistical parameters of simulation period are in satisfactory level. Therefore, the BUDGET model is able to predict actual evapotranspiration for any level of soil moisture with reasonable accuracy. The model can be used in planning, management and operation of an irrigation project for judicious use of water with the limited inputs, especially suitable for countries where modeling of crop yield is needed under water stress conditions.
\end{abstract}

Keywords: Evapotranspiration, Water balance, Wheat, Simulation model

\section{Introduction}

Appropriate management of irrigation is of vital importance to preserve water resources, quantitatively and qualitatively. Irrigation scheduling is important for developing best management practices for irrigated areas. Information on field water balance components and specially the evapotranspiration (ET) under specific soil, climate and crop condition is essential for proper irrigation scheduling.

Evapotranspiration is related to climatic factors, geologic locations, seasonal rainfall, available amount of soil moisture and types of crop. Estimation of actual ET may be useful in irrigation scheduling and proper designing of irrigation projects. With increasing pressure on water resources for competing users, large emphasis has been placed on water use efficiency in irrigated fields (Hatfield et al., 1996). Again, excessive applications have caused deep percolation of water carrying plant nutrients and other chemicals, thus further increasing costs (Engel et al., 1989) and reducing command area. There is considerable scope for improving water use efficiency of crops by proper irrigation scheduling which is essentially governed by crop evapotranspiration. Accurate estimation of crop ET is an important factor in efficient water management. Evapotranspiration models which estimate actual crop evapotranspiration may be usefully utilized for these purposes.

Crop growth simulation models, which integrate the effects of meteorological, soil and management variables to simulate plant growth and development, have been developed for many crops (Baker, 1980). Because water stress is frequently a limiting factor on crop growth, one of the major concerns in modeling is the accurate simulation of the soil water balance. Status of the soil water balance is dependent on water supply by irrigation and rainfall and water demand by evapotranspiration as well as antecedent soil moisture. All terms influencing the soil water balance must be estimated accurately for water stress effects to be simulated properly. Soil water models help in translating irrigation amounts (that are applied at different growth stages) to ET that has significance for biomass production. 
Numerous models have been developed and used by the researchers for simulation of water balance in the cropped field such as ISAREG model (Teixeira and Pereira, 1992), IRRICEP model (Paulo et al., 1993), IMSOP model (Malano et al., 1993), MACRO model (Jarvis et al., 1994), CROPWAT model, BUDGET (Raes, 2002), etc.

The objective of the study is to evaluate the performance of simulation model "BUDGET" in wheat crop field.

\section{Materials and Methods}

\section{General overview of model 'BUDGET'}

BUDGET is composed of a set of subroutines describing the various processes involved in water extraction by plant roots and water movement in the absence of a water table (Raes, 2002). BUDGET calculates the water storage in a soil profile as affected by the infiltration of rain and irrigation water and withdrawal of water by crop evapotranspiration and deep percolation for a given period. To solve the onedimensional vertical water flow and root water uptake a finite difference technique is used. During periods of crop water stress the resulting yield depression is estimated by means of yield response factors. By selecting appropriate time and depth criteria irrigation schedules can be generated.

The climatic data option in BUDGET consists of daily, mean 10-day or monthly $\mathrm{ET}_{0}$ (reference crop evapotranspiration) and rainfall observations. At run time, the 10-day and monthly data are processed to derive daily $\mathrm{ET}_{0}$ and Rainfall data. By specifying and selecting a few appropriate crop parameters in a menu driven environment, the program creates a complete set of parameters that can be displayed and updated if additional information is available. The soil profile may be composed of several soil layers, each with their specific characteristics. BUDGET contains a complete set of default characteristics that can be selected and adjusted for various types of soil layers. More details about BUDGET model can be found in Raes (2002) and Raes et al. (2006).

During the simulation, BUDGET records continuously the daily soil water content in the soil profile, soil water fluxes, daily values of the various parameters of the soil water balance and the daily root zone depletion and net irrigation requirement. The daily records are stored in various output files which can be displayed at the end of the simulation run with different time aggregations (day, 10-day, month, or year) and saved for further analysis.

\section{Climate input (ET 0 and Rain data)}

For each day of the simulation period, the program requires information concerning the weather conditions. The climatic conditions are given by:

- Evaporative demand of the atmosphere for the given weather conditions. The atmospheric demand is given by the evapotranspiration from the reference surface (ETo); and

- Rainfall depth, which is the amount of water collected in rain gauges installed on the field or at a nearby weather station.

The data consist of daily, mean 10-day or mean monthly ETo and Rainfall observations. Simulations can run with climatic data of a specific year, mean average data not linked to a specific year, or even with ETo or Rainfall levels than are expected with a given probability (dependable ETo or Rainfall). At run time, the 10-day and monthly data are processed to derive daily ETo and Rain data.

\section{Field data}

The input file was prepared from the field data of Ali (2008). These data were obtained from an experiment, conducted during three consecutive years, at the experimental farm of Bangladesh Institute of Nuclear Agricultural (BINA), Ishurdi, Bangladesh. Its coordinates are latitude $24^{\circ} 06^{\prime} \mathrm{N}$, longitude $89^{\circ} 01^{\prime}$ $\mathrm{E}$ and altitude is 10.36 meters $(\mathrm{m})$ above mean sea level. 
The climate of experimental area is humid and sub-tropic with summer dominant rainfall. Yearly average rainfall is $1572 \mathrm{~mm}$, concentrated over the months of April to September. The wheat growing period, November to March is characterized by dry winter. The soil is a calcareous brown floodplain silt loam developed from the Ganges river alluvium and classified as calcareous fluvisol according to FAO/UNESCD classification (FAO, 1971). The soil is alkaline $\left(\mathrm{p}^{\mathrm{H}}=8.5\right)$, medium in organic matter content $(1.8 \%)$ having infiltration rate of $0.48 \mathrm{~cm} / \mathrm{hr}$. The growing period of wheat cultivar "SATABDHI" (Triticum aestivum) was about 120 to125 days. Four irrigations were applied over the growing period.

\section{Statistical parameters used to compare the model output}

The output of a model depends on the principle of the model itself and the accuracy of the input data. Evaluation of model performance should include both statistical criteria and graphical display. A model is a good representation of reality only if it predicts an observable phenomenon with acceptable accuracy and precision (Loague and Green, 1991).

Addicott and Whitmor (1987) concluded that any one method of measuring discrepancy between model output and observed data alone might be misleading, but several methods used together could summarize the closeness of a model's estimates and measurements with the observed values. So, in addition to graphical comparison, the following statistics and model performance indicators were used to indicate overall model performance: Coefficient of correlation, standard deviation, standard error, coefficient of variation, mean bias or average deviation, root mean square error (RMSE), scaled root mean square error (SRMSE), Relative error, model efficiency, and index of agreement (IA) [Ali et al, 2004, Dust et al., 2000; Lecina et al., 2003; Loague and Green, 1991; Law, 1983].

Mean bias (or average deviation):

$$
\text { Bias }=\frac{1}{N} \sum_{i=1}^{N}\left(S_{i}-M_{i}\right)
$$

where $S$ and $M$ are the simulated and measured values for the ith observation and $N$ is the number of observations.

(ii) Mean Absolute Bias or error:

$$
\text { MAE }=\frac{1}{N} \sum_{i=1}^{i=N} \mathrm{I} S_{i}-M_{i} \mathrm{I}
$$

where $S$ and $M$ are the simulated and measured values for the ith observation and $N$ is the number of observations.

(iii) Root mean square error (RMSE): It quantifies the dispersion between simulated and measured data:

$$
\text { RMSE }=\sqrt{\frac{1}{N}} \sum_{i=1}^{N}\left(S_{i}-M_{i}\right)^{2}
$$

where $S$ and $M$ are the simulated and measured values for the ith observation and $N$ is the number of observations. Ideally, the value of RMSE should be zero.

iv) Relative error (RE):

$$
\mathrm{RE}=\frac{R M S E}{\bar{y}} .100
$$

where $\bar{y}$ is the mean of observed values

v) Model efficiency: Model efficiency (EF) was calculated as:

$$
E F=\frac{\left.\sum \text { (measured }- \text { measured..mean }\right)^{2}-\sum(\text { simulated }- \text { measured })^{2}}{\left.\sum \text { (measured }- \text { measured..mean }\right)^{2}}
$$

An ideal value of $E F$ is unity. 


\section{(vi) Index of Agreement (IA):}

$$
I A=1-\frac{\sum_{i=1}^{N}\left(O_{i}-s_{i}\right)^{2}}{\sum_{i=1}^{N}\left[O i+S_{i}^{\prime}\right]^{2}}, \quad 0 \leq I A \leq 1
$$

where $O_{i}^{\prime}=\left|O_{i}-\bar{S}\right|, S_{i}^{\prime}=\left|S_{i}-\bar{S},\right| O_{i}$ is the observed value, $S_{i}$ is the simulated value and $\bar{S}$ is the simulated mean.

\section{Results and Discussion}

\section{Graphical display of simulation results}

Fig. 1 presents the plot of simulated and observed actual evapotranspiration values for the different stages of growing period of wheat. In this Figure, the coefficient of determination $\left(R^{2}\right)$ for the early, middle and late stages is higher than that of other stages. So, it is evident that the simulated and observed actual evapotranspiration are high and water loss is also high. In these stages, irrigation is provided in a sufficient way for better crop growth development so that the field water balance becomes standard with the surrounding environment. From sowing to first irrigation, evapotranspiration is low, because transpiration is negligible at the initial growing time and evaporation is mainly taken place.

Fig. 2 presents a plot of observed (actual evapotranspiration) versus simulated values of the combination of three years data (2002-03, 2003-04 and 2004-05). The result shows that the model can estimate actual evapotranspiration with reasonable accuracy $\left(R^{2}=0.8316\right)$. Figs. $3(a), 3(b)$ and $3(c)$ present the bar diagrams showing comparison between simulated and observed evapotranspiration for different stages of growing period of wheat. The highest difference occurred between observed and simulated values at the period from sowing to first irrigation, which may be attributed due to higher evaporation rate than the transpiration (due to lower surface cover by leaf) at this stage.

Fig. 4 presents the plot of simulated against observed actual evapotranspiration values distribution around the 1:1 line for combined data. This Figure shows that maximum data points lie around the 1:1 line, which means that the model output is accurate and reasonable. Fig. 5 presents combined data distribution of simulated values around the 1:1 line.

\section{Statistical parameters of model output}

In this study some statistical parameters have been used to find out the reliability of the model output. The results of statistical analyses are summarized in Table 1.

Table 1. Statistical summary comparing observed and simulated data

\begin{tabular}{|c|l|c|}
\hline SI. no. & Statistical parameter & Calculated value \\
\hline 1 & Observed ET mean $(\mathrm{mm})$ & 57.59 \\
\hline 2 & Simulated ET mean $(\mathrm{mm})$ & 55.39 \\
\hline 3 & Standard deviation of observed ET $\left(\mathrm{SD}_{\text {obs }}\right)$ & 29.23 \\
\hline 4 & Standard deviation of simulated ET $\left(\mathrm{SD}_{\text {sim }}\right)$ & 21.07 \\
\hline 5 & Standard error of observed ET $\left(\mathrm{SE}_{\mathrm{obs}}\right)$ & 6.23 \\
\hline 6 & Standard error of simulated ET $\left(\mathrm{SE}_{\text {sim }}\right)$ & 4.49 \\
\hline 7 & Coefficient of variation $(\mathrm{CV})$ of observed ET $(\%)$ & 50.75 \\
\hline 8 & Coefficient of variation $(\mathrm{CV})$ of simulated ET $(\%)$ & 38.03 \\
\hline
\end{tabular}

In this Table it is evident that the simulated mean $(\bar{S})$, standard deviation (SD), standard error (SE) and coefficient of variation (CV) are lower than those of the observed evapotranspiration values. 

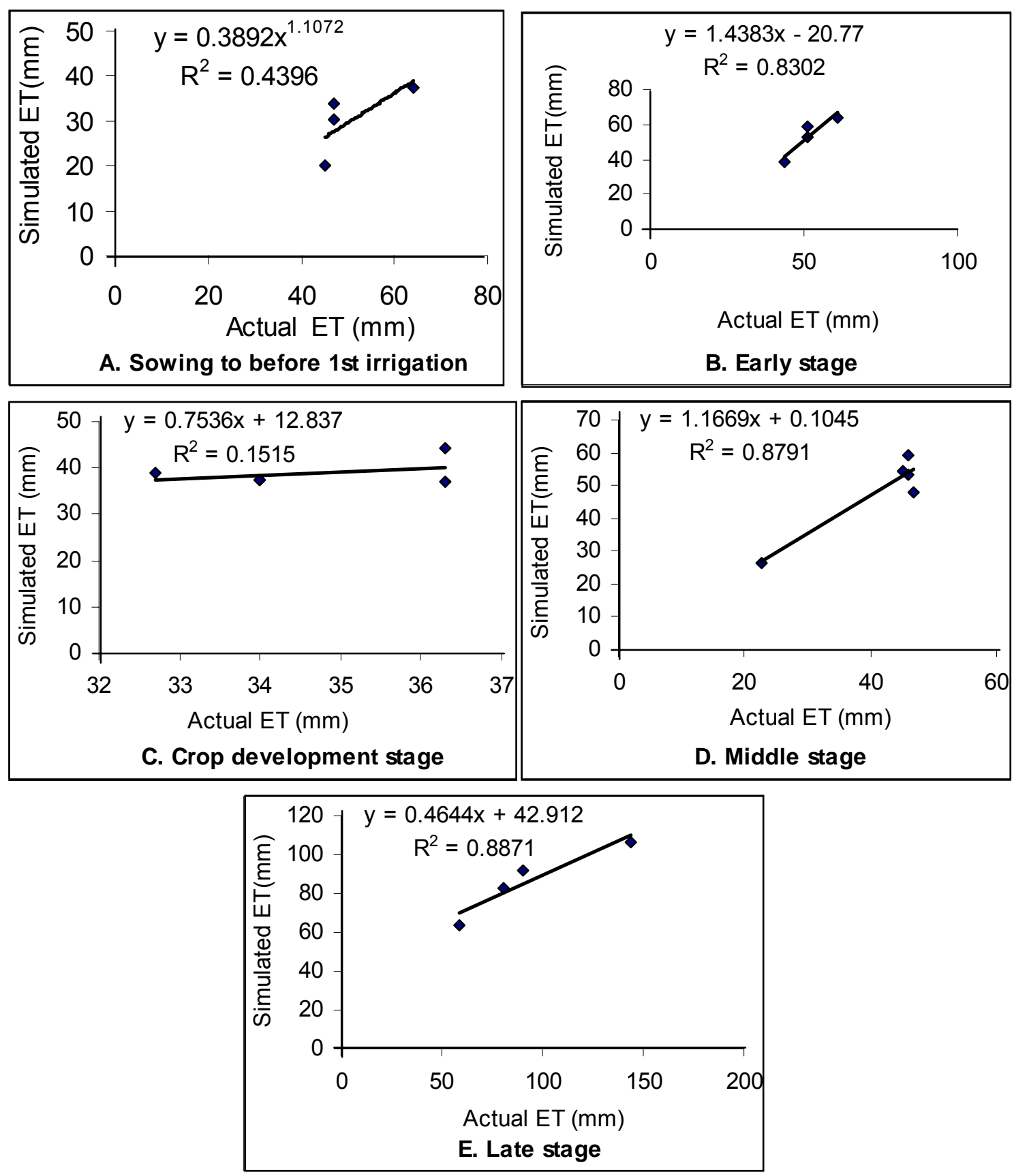

Fig. 1. Comparison between simulated and observed evapotranspiration (ET) at different stages of wheat growth 


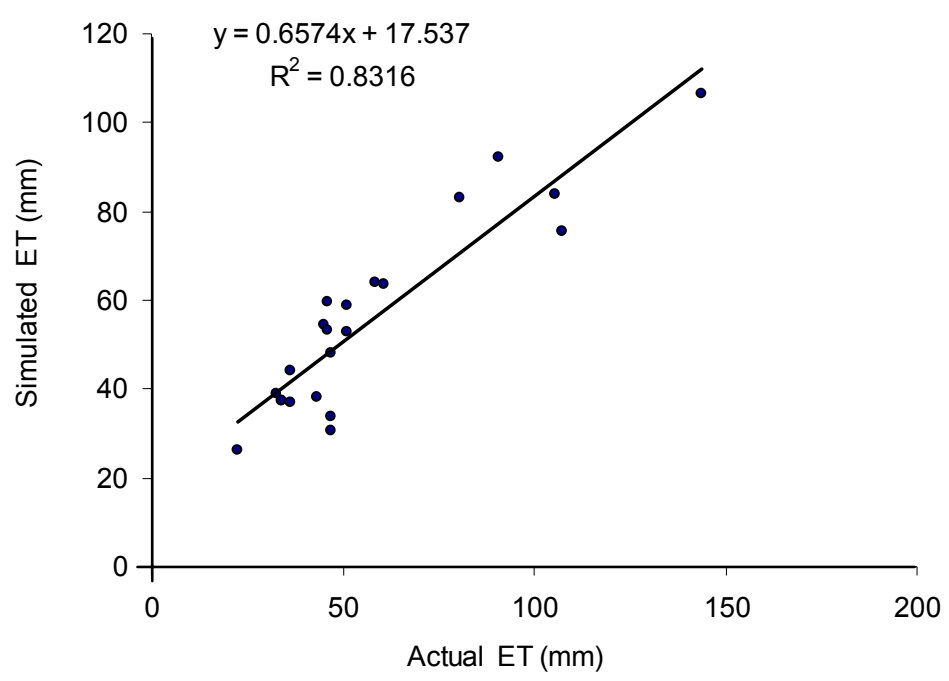

Fig. 2. Comparison between simulated and actual evapotranspiration (ET) (for combined data)
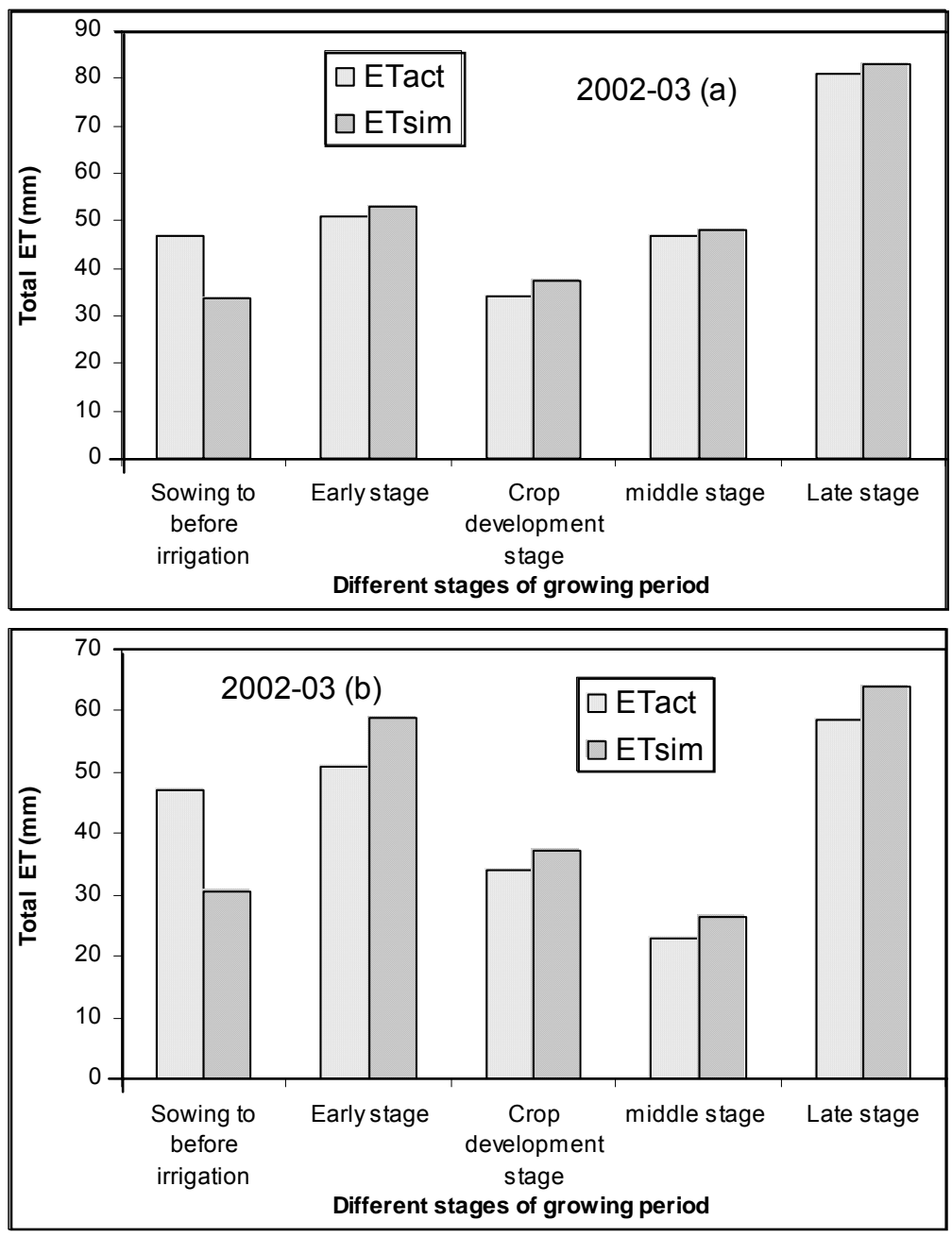

Fig. 3(a). Comparison between simulated and observed evapotranspiration (ET) for different stages of growing period of wheat (2002-03) 

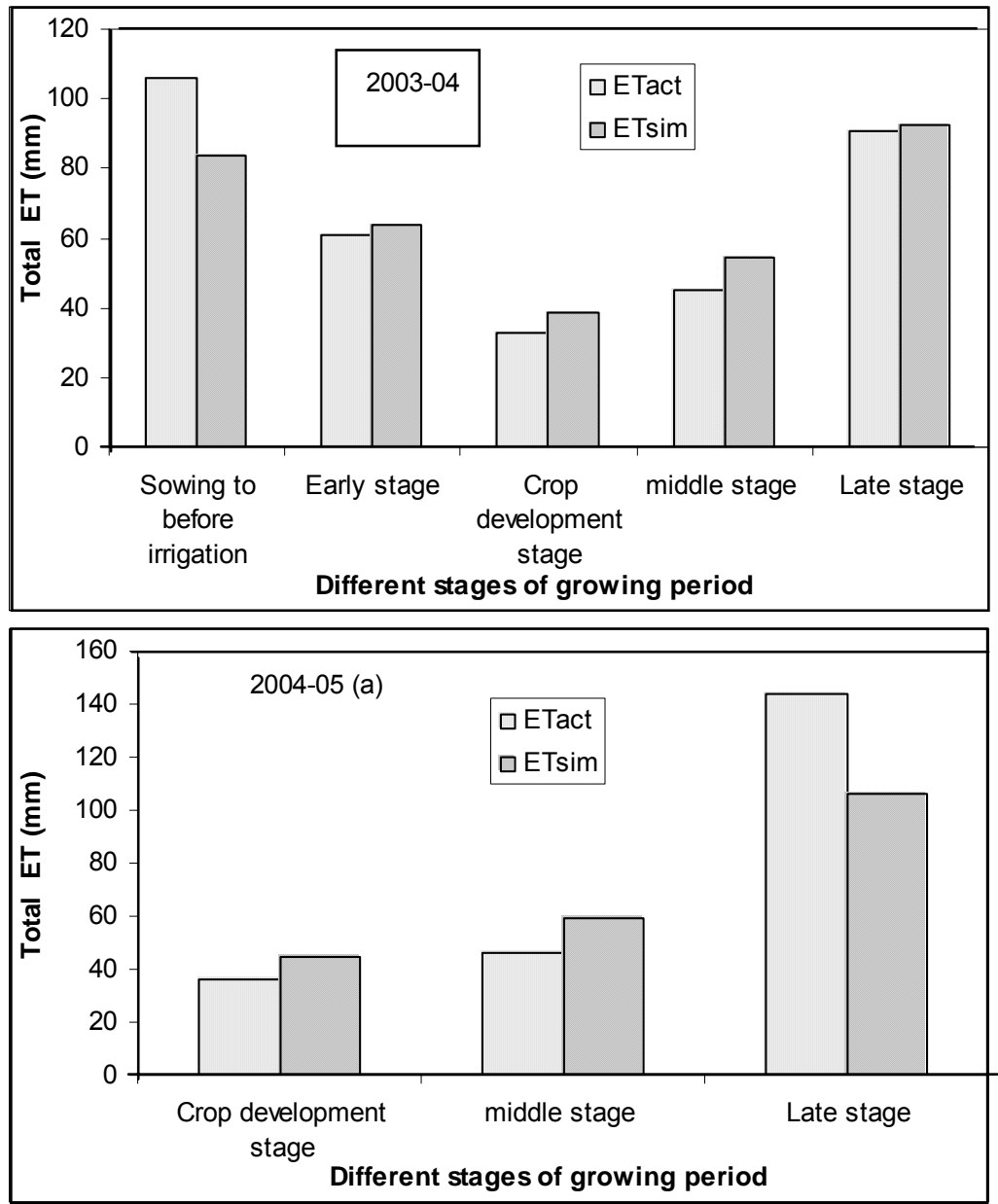

Fig. 3(b). Comparison between simulated and observed evapotranspiration (ET) for different stages of growing period of wheat (2003-04, 2004-05 a)

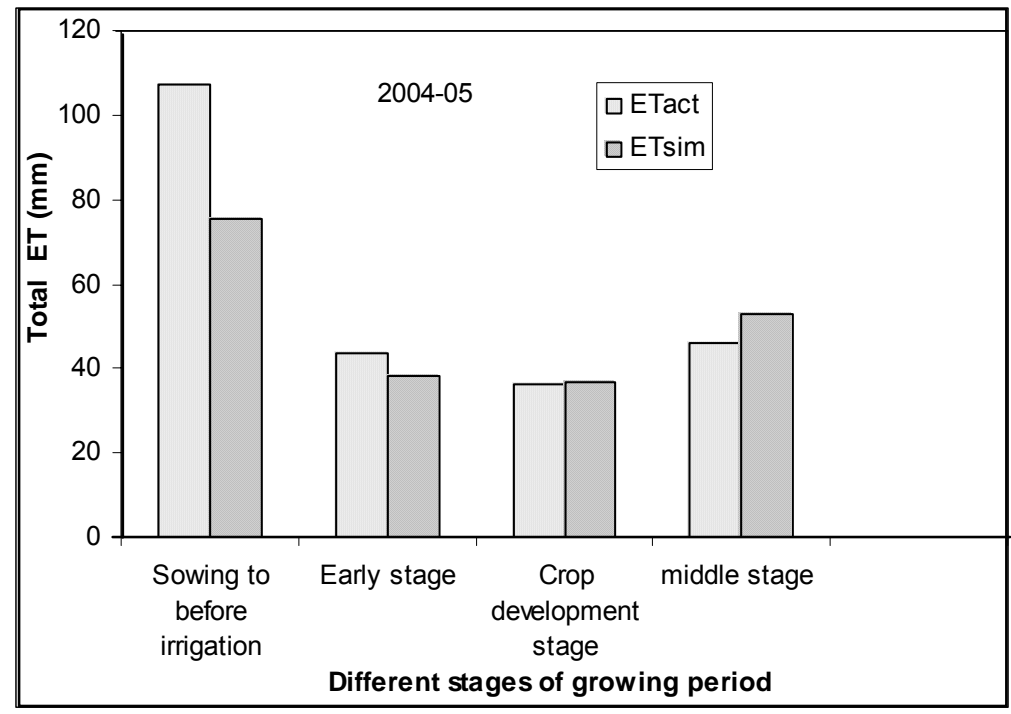

Fig. 3(c). Comparison between simulated and observed evapotranspiration (ET) for different stages of growing period of wheat (2004-05) 


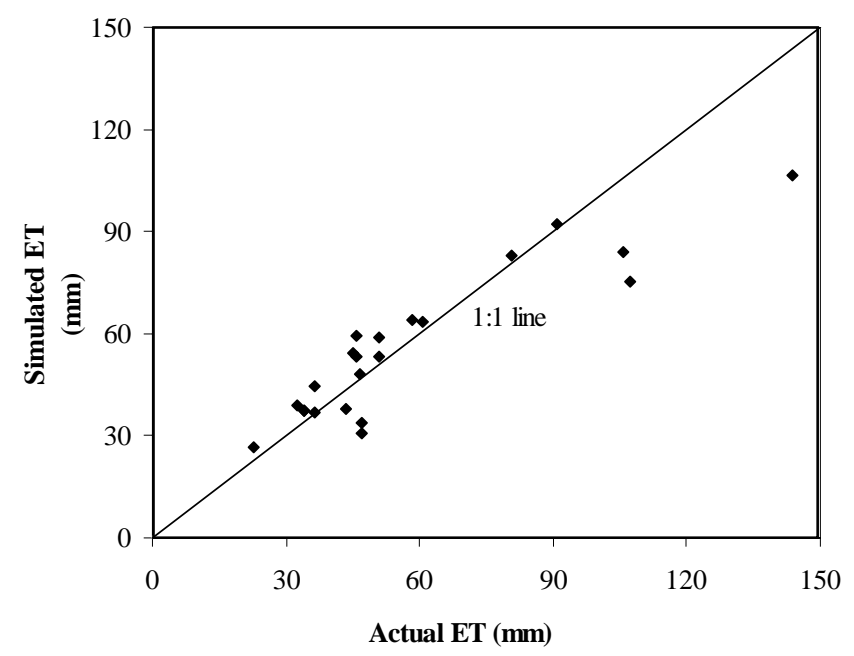

Fig. 4. Comparison between actual evapotranspiration (ET) and simulated model output values (Combined data) distributed around the 1:1 line
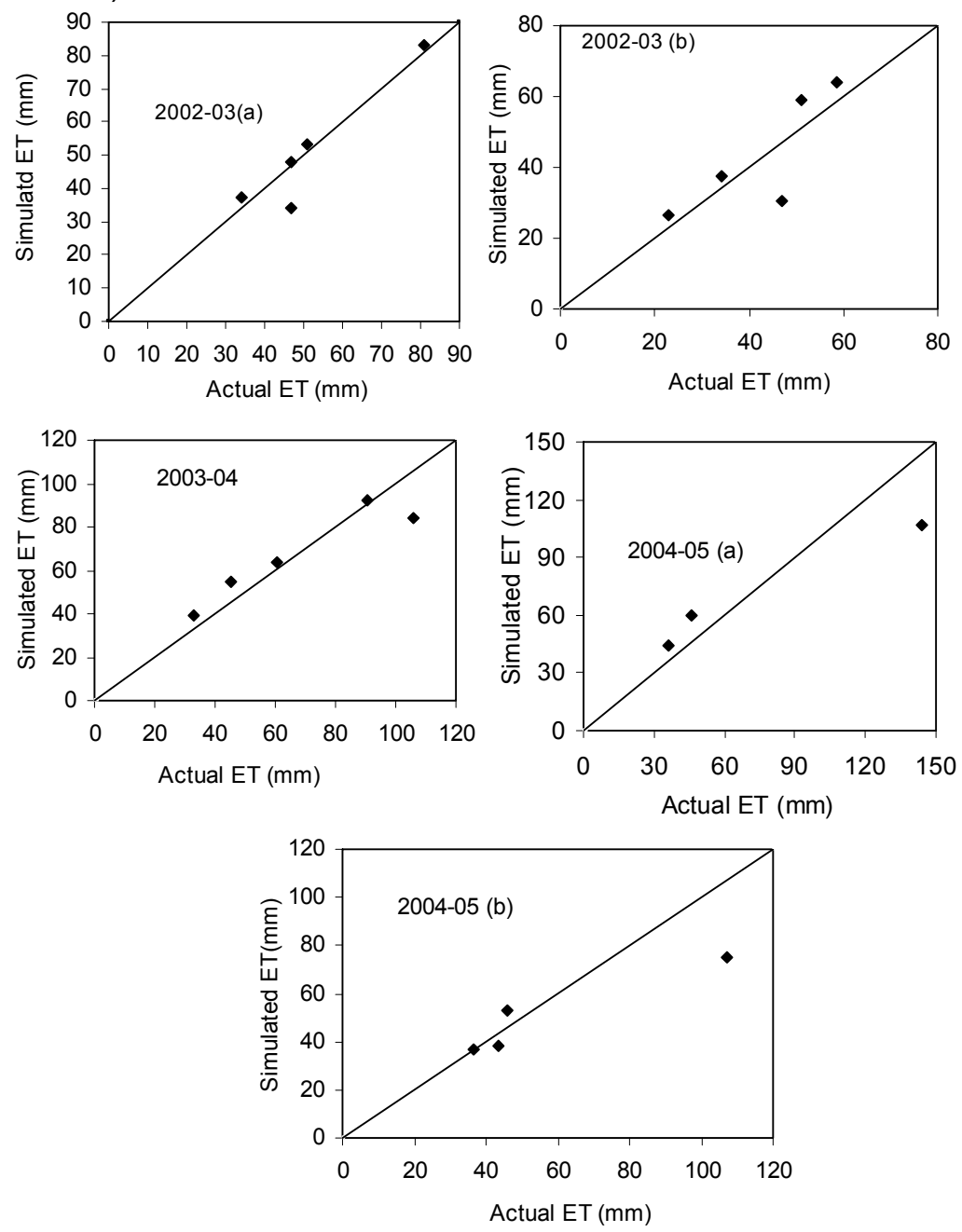

Fig. 5. Comparison between actual evapotranspiration (ET) and model output values (yearly data) distributed around the 1:1 line 
The statistical parameters of simulation performance are also summarized in Table 2.

Table 2. Statistical parameters of simulation performance

\begin{tabular}{|l|l|l|}
\hline Sl. no. & Statistical parameter & Calculated value \\
\hline 1 & $\mathrm{R}^{2}$ & 0.8316 \\
\hline 2 & MBE $(\mathrm{mm})$ & -2.19 \\
\hline 3 & RMSE $(\mathrm{mm})$ & 13.41 \\
\hline 4 & RE $(\%)$ & 23.28 \\
\hline 5 & Model efficiency, EF $(\%)$ & 78.95 \\
\hline 6 & Index of agreement $(\mathrm{IA})$ & 0.918 \\
\hline
\end{tabular}

The analysis of coefficient of determination shows that the value of $R^{2}$ is in general within the acceptable limit $\left(R^{2}>0.8\right)$. The value of $R^{2}(0.8316)$ indicates that a good correlations exists between the simulated and observed evapotranspirations $(r=0.91)$. The value of mean bias error $(\mathrm{MBE})$ is equal to -2.19 . $A$ positive value of MBE indicates overestimation and vice-versa and the absolute value is an indicator of overall bias in the model estimation. The magnitude of root mean square error (RMSE) is also a useful parameter to evaluate model performance. In an ideal condition, the values of relative error (RE) and model efficiency (EF) will be $0 \%$ and $100 \%$, respectively. The RE value of 23.28 percent and EF value of 78.95 percent indicate that the performance of BUDGET model in simulating actual evapotranspiration is satisfactory. The limit of index of agreement (IA) value is from 0 to 1 . A higher value indicates a better agreement between the simulated and observed values. In this study the value of IA (0.918) shows a very good performance of the model. The above statistical parameters suggest that, the overall performance of the BUDGET model in simulating actual evapotranspiration from wheat crop field is satisfactory.

Based on the graphical display and statistical indicators, it can be concluded that the simulation model BUDGET is able to predict actual evapotranspiration with reasonable accuracy. Thus, the model can be used in planning, management and operation of an irrigation project for judicious use of water.

\section{References}

Ali, M.H. 2008. Deficit irrigation for wheat cultivation under limited water supply condition. PhD Dissertation, Dept. of Irrigation and Water Management, Bangladesh Agricultural University, Mymensingh.

Addicott, T.M. and Whitmor, A.P. 1987. Computer simulation of changes in soil mineral nitrogen and crop nitrogen during autumn, winter and spring. J. Agric. Sci. Cambridge. 109: 141-157.

Ali, M.H., Amin, M.G.M. and Islam, A.K.M.R. 2004. Comparoson of various methods for estimating reference crop evapotranspiration. J. Bangladesh Agril. Uni. 2(2): 313-324.

Baker, D.N. 1980. Simulation for research and crop management. In: F.T.Corbin (ed.), world Soybean Research Conference II: Proceeding, Westview Press, Boulder, CO, pp. 533-546.

Dust M., Baran, N., Errera, G., Huston, J.L., Mouvet, C., Schafet, H., Vereecken, H. and Walker, A. 2000. Simulation of water and solute transport in field soils with the LEACHP model. Agric Water Manage., 44: 225-245.

Engel, B.A., Lembke, W.D., Sipp, S.K. and Goetsch, W.D. 1989. Irrigation crop coefficients for Illinois corn. Soil and water Division of ASAE, 1275-1280.

FAO. 1971. Soil Survery Project of Bangladesh. Soil Resources Technical Report-3 of Food and Agricultural Organization of the United Nations (FAO). Rome. 211p.

Hatfield, J.L., Prueger, J.H. and Reicosky, D.C. 1996. Evapotranspiration effects on water quality. In: Proceeding of the ASAE International Conference on Evapotranspiration and Irrigation Scheduling. 3-6 November, San Antonio, TX. pp. 536-546.

Jarvis, N.J., Stahli, M., Bergstrom, L. and Johnsson, H. 1994. Simulation of Dichlorprop and Bentazon leaching in soils of contrasting texture using the MACRO model. J. Environ. Sci. Health. A29(6): 1255-1277.

Law, A.M. 1983. Statistical analysis of simulation output data. Operations Res., 31: 983 - 1029.

Lecina, S., Martinez-Cob, A., Perez, P.J., Villalobos, F.J. and Baselga, J.J. 2003. Fixed versus variable bulk canopy resistance for reference ET estimation using the Penman-Monteith equation under semi-arid conditions. Agric. Water Manage. 60: 181 198. 
Loague, K. and Green, R.E. 1991. Statistical and graphical methods for evaluating solute transport models: Overview and application. J. Contam. Hydrol. 7: 51-73.

Malano, J.B., Boonlue, A.M. and Vlotman, N.B. 1993. Irrigation main system operation model (IMSOP): Case study and integrated computerization framework. Food and Agricultural Organization of the United Nations (FAO). Irrigation water delivery models. Water reports-2. Rome, Italy. 116p.

Paulo, S., Teixeira, J.L. and Pereira, L.S. 1993. Modelling for irrigation delivery scheduling: Simulation of demand at sector level with models ISAREG and IRRICEP. Food and Agricultural Organization of the United Nations (FAO). Irrigation water delivery models. Water reports-2. Rome, Italy. 23p.

Raes, D., Geerts, S., Kipkorir, E., Wellens, J. and Sahli, A. 2006. Simulation of yield decline as a result of water stress with a robust soil water balance model. Agric. Water Mgt. 81 (3): 335-357.

Raes, D. 2002. BUDGET: A soil water and salt balance model. Reference Manual, Version 5.0. Institute for Land and Water Management, Leuven, Belgium.

Teixeira, J.L. and Pereira, L.S. 1992. Modelling for irrigation delivery scheduling: Simulation of demand at sector level with models ISAREG and IRRICEP. Food and Agricultural Organization of the United Nations (FAO). Irrigation water delivery models. Water reports-2. Rome, Italy. 15p. 